
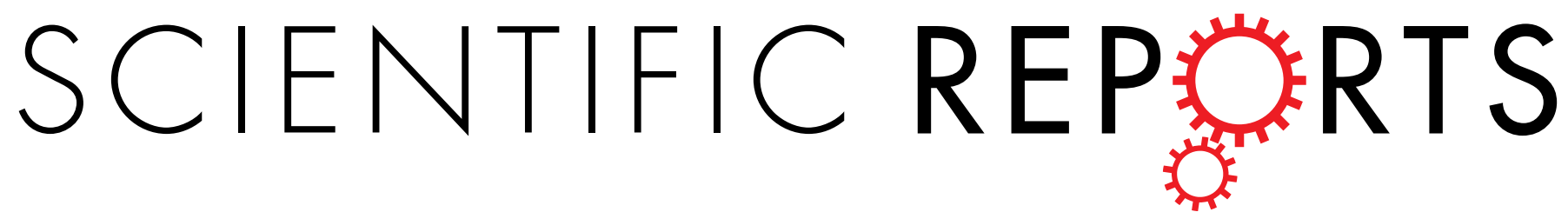

OPEN

\title{
First Direct Evidence of Long- distance Seasonal Movements and Hibernation in a Migratory Bat
}

Received: 10 May 2016

Accepted: 14 September 2016

Published: 04 October 2016
Theodore J. Weller ${ }^{1}$, Kevin T. Castle ${ }^{2}$, Felix Liechti ${ }^{3}$, Cris D. Hein ${ }^{4}$, Michael R. Schirmacher $^{4}$ \& Paul M. Cryan ${ }^{5}$

Understanding of migration in small bats has been constrained by limitations of techniques that were labor-intensive, provided coarse levels of resolution, or were limited to population-level inferences. Knowledge of movements and behaviors of individual bats have been unknowable because of limitations in size of tracking devices and methods to attach them for long periods. We used sutures to attach miniature global positioning system (GPS) tags and data loggers that recorded light levels, activity, and temperature to male hoary bats (Lasiurus cinereus). Results from recovered GPS tags illustrated profound differences among movement patterns by individuals, including one that completed a $>1000 \mathrm{~km}$ round-trip journey during October 2014. Data loggers allowed us to record sub-hourly patterns of activity and torpor use, in one case over a period of 224 days that spanned an entire winter. In this latter bat, we documented 5 torpor bouts that lasted $\geq 16$ days and a flightless period that lasted 40 nights. These first uses of miniature tags on small bats allowed us to discover that male hoary bats can make multi-directional movements during the migratory season and sometimes hibernate for an entire winter.

Individuals of several species of North American bats make biannual migratory journeys between winter and summer habitat ${ }^{1}$, yet compared to birds, our understanding of the details and destinations is nascent. In relative terms, we have extensive knowledge of bird migration that stems from the ease with which humans can observe seasonal changes in species occurrence and obvious group movements over continental scales, as well as the ability of larger animals to carry tracking devices ${ }^{2-4}$. Studying migration in the smallest flying animals remains a challenge. Long-distance movements of small $(<30 \mathrm{~g})$ birds were initially revealed through extensive banding (ringing) efforts ${ }^{2}$, and later by incorporating isotope analyses ${ }^{5}$. Recently, breakthroughs concerning the seasonal whereabouts, flight paths, and long-term activity patterns of small migratory birds have also been made possible by miniature global-positioning-system (GPS) tags $^{6}$ and data-recording environmental sensors (hereafter data loggers ${ }^{7-9}$ ). Recent increases in our understanding of bird-migration discoveries were made using miniaturized $(1-2 \mathrm{~g})$ tracking and sensor devices ${ }^{10-12}$, which augurs well for advancing understanding of migration and seasonal behaviors in a particularly difficult-to-study group of long-distance migrants-small bats. As in birds ${ }^{13}$, there is growing recognition that effective conservation of bats requires understanding of their needs beyond the summer breeding season and winter hibernation periods when they are easiest to study ${ }^{14}$.

It has long been known that certain species of bats migrate ${ }^{15,16}$, but studying bats is extremely challenging because of their ubiquitously cryptic nocturnal activity patterns and secretive roosting. These difficulties have left broad gaps in our understanding of many bats, but particularly the small-bodied, long-distance migrants. Efforts to study bat migration have employed methods such as banding individuals ${ }^{17-19}$, visual observations and captures $^{20,21}$, compiling seasonal maps of occurrence records ${ }^{22,23}$, genetic analyses ${ }^{24,25}$, radiotracking ${ }^{26,27}$, and stable isotope analyses ${ }^{28-32}$. However, the success rates and spatial or temporal resolution of such methods remain low. Although new technology recently enabled following the long-distance movements of large (>100 g) bats ${ }^{33,34}$, data on the movement patterns and behaviors of small migratory bats do not exist. Yet, as with birds ${ }^{3,6}$, knowledge

${ }^{1}$ USDA Forest Service, Pacific Southwest Research Station, 1700 Bayview Drive, Arcata, California, 95521, USA. ${ }^{2}$ Wildlife Veterinary Consulting, 840 Sundance Drive, Livermore, Colorado, 80536, USA. ${ }^{3}$ Swiss Ornithological Institute, Seerose 1, 6204 Sempach, Switzerland. "Bat Conservation International, PO Box 162603, Austin, Texas,

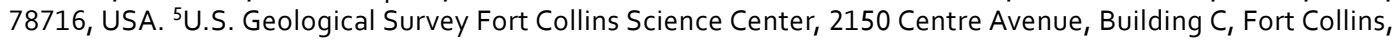
Colorado, 80526, USA. Correspondence and requests for materials should be addressed to T.J.W. (email: tweller@ fs.fed.us) 


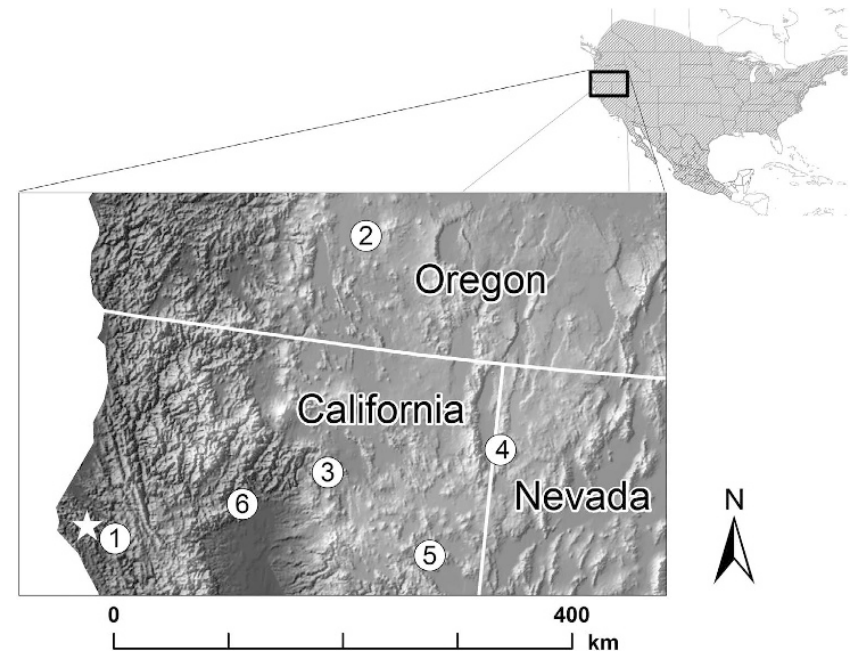

Figure 1. Locations of a free-ranging hoary bat (Lasiurus cinereus) recorded using a miniature GPS tag in October 2014. General location of sites where the male bat was captured and fit with GPS tag in September 2014 and then recaptured in April 2015 are illustrated with white star. Dates of bat locations (white circles) were: (1) Oct 1, (2) Oct 5, (3) Oct 12, (4) Oct 21, (5) Oct 25, and (6) Oct 28 2014. Inset map shows distribution of hoary bats in North America (hatched area) and region of detail (black rectangle). Map created using ArcGIS version number 10.3.1 (http://www.esri.com/software/arcgis).

of movements and behaviors of individual animals can provide important insights into their ecology and ultimately help provide for their conservation.

In North America, so-called "migratory tree bats" $\left(\mathrm{sensu}^{35}\right)$ are thought to undertake some of the longest seasonal movements of any bat species. Hoary bats (Lasiurus cinereus) roost individually in the foliage of trees at low density and, despite a wider distributional range than most mammals, are rarely encountered through vast areas of their range ${ }^{36}$; these characteristics combine to make them one of the most poorly understood migratory tree bats. Seasonal distribution patterns inferred from occurrence records and stable isotope analyses indicate that hoary bats generally migrate southward and towards coasts from their summer range to overwinter $22,23,28,29,37$. Migration is often defined as seasonally mediated, directional movements between habitats ${ }^{2}$. Hence, although it can be expected that animals select migratory routes that minimize energetic costs, the precise movements of individual hoary bats were unknown. Conventional understanding has been that hoary bats move to areas of moderate climate for the winter which allows them to make frequent use of daily torpor interspersed with occasional feeding when insects are active ${ }^{38}$. However, evidence of extensive cold-season activity by hoary bats in any of their potential wintering areas is lacking.

Here, we describe our successful use of two types of miniature data-recording devices that allowed us to gain new insights into the ecology and behavior of individual hoary bats. We sutured GPS tags to male hoary bats and obtained multiple site locations that allowed us to infer long-distance movements of individuals during the autumn migration period. To other bats, we attached data loggers that recorded light level, temperature, and activity, from which we obtained detailed information on individual hoary bats over periods spanning as long as an entire winter. These data recorded from small, free-ranging, migratory tree bats are the first of their kind and allow us to challenge two assumptions about hoary bats: (1) that their autumn migration routes are directional and generally linear and (2) that, unlike smaller cave-dwelling bats, they do not hibernate or use sequential bouts of multi-day torpor during winter.

\section{Results}

Autumn Movements. We attached GPS tags to 8 male hoary bats in late September 2014 and recovered 3 of them after they had recorded GPS locations (hereafter 'fixes'). In total, we obtained 2, 4, and 6 GPS fixes per bat that were recorded during October 2014. GPS data revealed 3 different behaviors of the bats we tracked: site fidelity, local $(<100 \mathrm{~km})$ movements, and long-distance $(>100 \mathrm{~km})$ movements. We recaptured Bat 479 on 4 different nights and obtained 4 GPS fixes from it over a period of 26 days. The longest movement recorded for Bat 479 was $6.4 \mathrm{~km}$ between its first GPS fix and its first recapture location. We recaptured Bat 481 twice following tag attachment leading us to document movements of $51.4 \mathrm{~km}$ and then a further $16.4 \mathrm{~km}$ southeast of our study area. The recapture of Bat 481 on Oct 52014 revealed it had traveled $67.8 \mathrm{~km}$ from its last GPS fix, recorded 25 hours earlier. We tagged Bat VHF5 on Sep 272014 and recaptured it on Apr 30 2015, 213 days after tag attachment. The resulting 6 GPS fixes, document that Bat VHF5 flew $>1000 \mathrm{~km}$ during October 2014 in a large circuit that began and ended in the vicinity of the capture area (Fig. 1).

Activity Patterns and Torpor Use. We attached data loggers to 6 male hoary bats on Sep 26 and 272014. We recovered 1 of them that had recorded 9 days of data during autumn 2014 and another that had recorded 224 days of data from autumn 2014 through spring 2015 (Fig. 2). We obtained simultaneous activity data from both bats from Sep 27 to Oct 62014 (Fig. 3). While both bats were mostly active throughout the entire night, on 

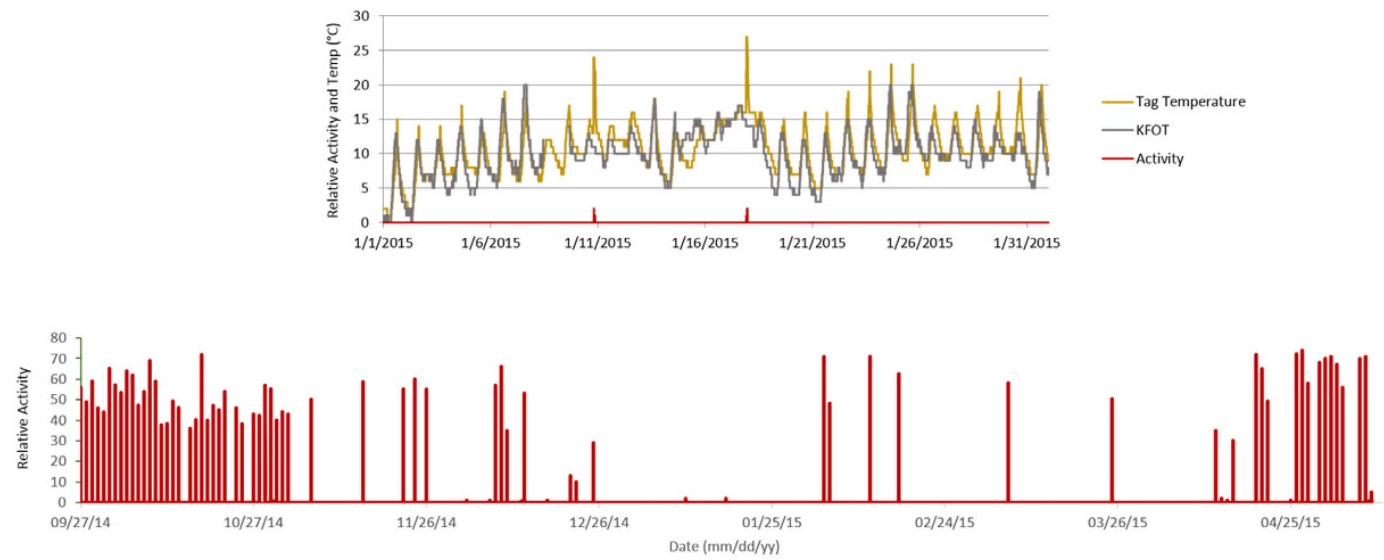

Figure 2. Activity of a male hoary bat during autumn 2014 - spring 2015 in relation to local environmental conditions. Relative activity levels (red lines) $<6$ are not associated with flight. Exploded view above shows tag temperature during January 2015 (yellow line), which tracked ambient temperatures at a nearby weather station (KFOT; gray line) except during 2 brief periods of rewarming by the bat without flight.
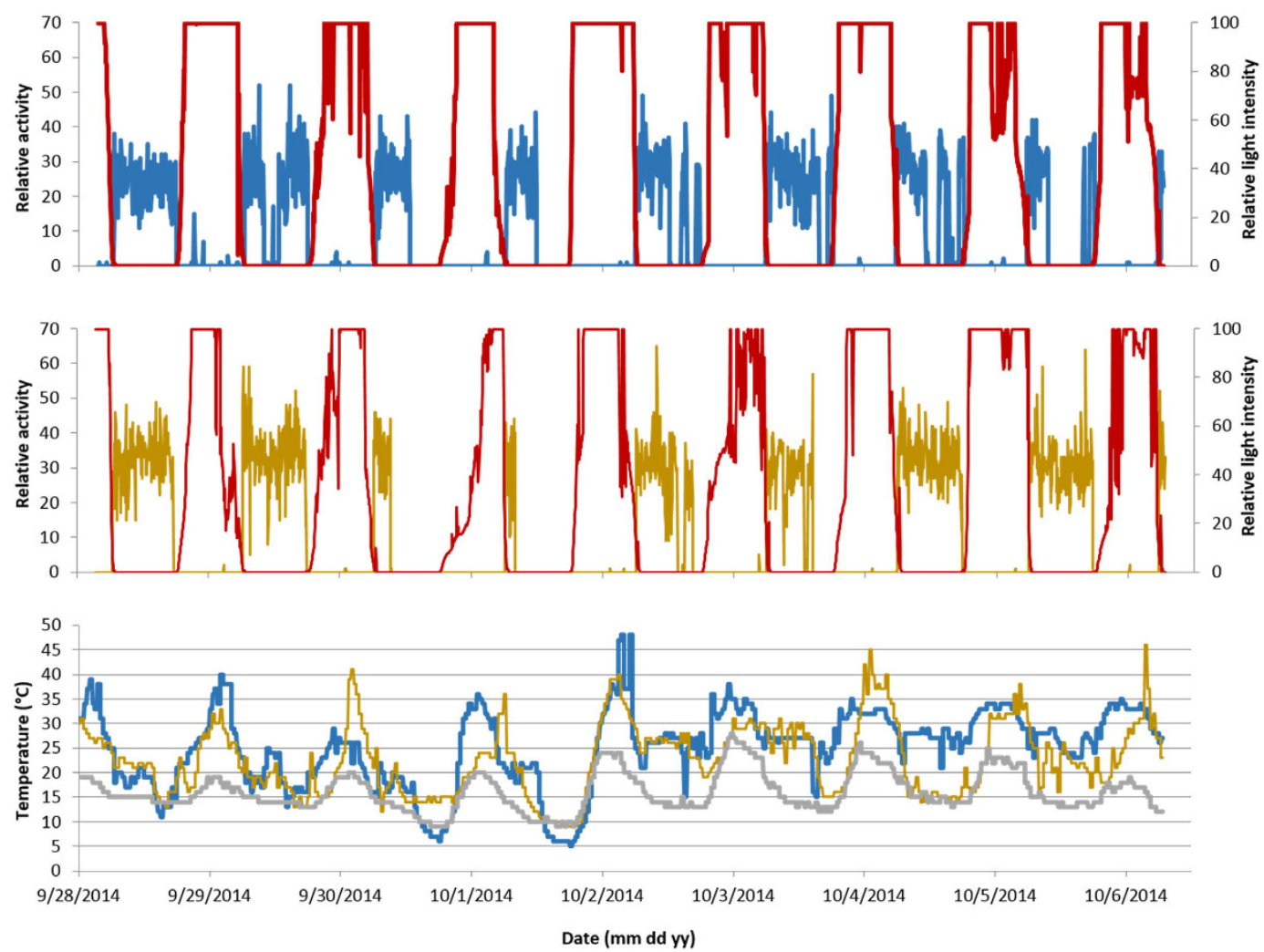

Figure 3. Comparison between activity patterns by two male hoary bats in northern California during autumn 2014. Relative light levels recorded by data loggers are depicted in red, ambient temperature from KFOT weather station in grey. Relative activity levels for blue-tagged bat (top panel), yellow tagged bat (middle panel), and tag temperatures for both bats (bottom panel). Date labels are centered on midnight.

Sep 30 and Oct 1 both were only active during the first half of the night. Ambient temperatures on both of these nights reached as low as $9^{\circ} \mathrm{C}$, whereas they remained $\geq 12^{\circ} \mathrm{C}$ on other nights during this period (Fig. 3). Both bats entered torpor on the evening of Oct 1 as evidenced by cessation of activity and tag temperatures conforming to ambient temperatures. Differences in temperature sensor readings between the bats carrying data loggers were sometimes noted. We speculate that differences in tag temperature sensor readings between bats carrying data loggers could be associated with them occupying different areas. For example, on the evening of Oct 4 , when the blue-tagged bat was active and presumably flying in an area that was about $10^{\circ} \mathrm{C}$ warmer than the area where the yellow-tagged bat was active (Fig. 3). 


\begin{tabular}{|l|c|c|c|c|}
\hline Month & $\begin{array}{c}\text { Nights } \\
\text { Tagged }\end{array}$ & $\begin{array}{c}\text { Active } \\
\text { Nights }\end{array}$ & $\begin{array}{c}\text { Percent } \\
\text { Nights Active }\end{array}$ & $\begin{array}{c}\text { Mean (range) Proportion } \\
\text { of Night Active }\end{array}$ \\
\hline September & 3 & 3 & 100.0 & $0.705(0.251-0.938)$ \\
\hline October & 31 & 28 & 90.3 & $0.443(0.013-0.959)$ \\
\hline November & 30 & 7 & 23.3 & $0.293(0.097-0.847)$ \\
\hline December & 31 & 5 & 16.1 & $0.095(0.005-0.227)$ \\
\hline January & 31 & 0 & 0.0 & 0.000 \\
\hline February & 28 & 4 & 14.3 & $0.074(0.037-0.103)$ \\
\hline March & 31 & 2 & 6.4 & $0.097(0.094-0.101)$ \\
\hline April & 30 & 9 & 30.0 & $0.302(0.039-0.626)$ \\
\hline May & 8 & 6 & 75.0 & $0.359(0.067-0.517)$ \\
\hline
\end{tabular}

Table 1. Number of nights on which a male hoary bat (yellow-tagged) exhibited activity from 28 Sept 2014-8 May 2015, as recorded by a data logger on the bat's back. 'Mean proportion of 5-minute periods during the night that the bat was active were calculated only for nights when bat was active.

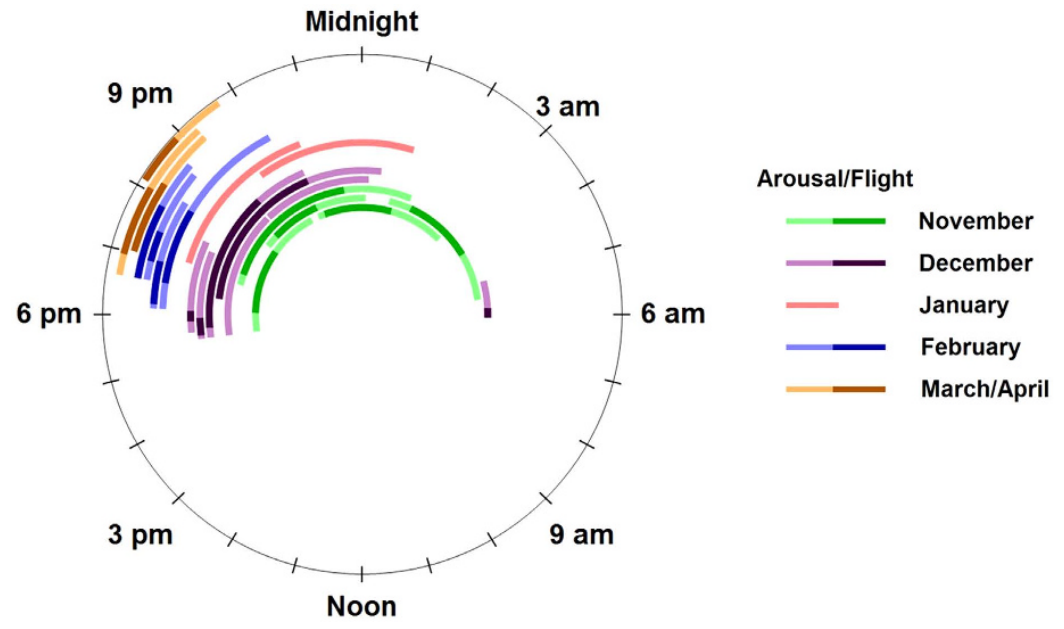

Figure 4. Arousal and flight events by a male hoary bat from 6 Nov. 2014-12 April 2015. Each arc extends between the beginning and end of an arousal from torpor. Darker shades represent the time period in which the bat was active, likely in flight, and lighter shades represent periods without flight activity, but when the tag was at arousal temperatures before and after a flight event. On 4 occasions, 2 in December and 2 in January, the bat aroused without exhibiting activity levels associated with flight.

We obtained a near-continuous record of activity, light exposure, and tag temperatures of a male hoary bat over 224 days from autumn through spring. Activity occurred on 31 of 34 nights in September and October, but then declined sharply in early November and did not increase substantially until late April (Fig. 2, Table 1). The bat was inactive on most nights during winter. Between Nov 32014 and Apr 12 2015, the bat exhibited levels of activity associated with flight on only $16(10 \%)$ of the 160 nights monitored. The longest period of inactivity lasted 40 nights, from Dec 262014 to Feb 03 2015. We recorded 19-, 18-, and 18-night periods of inactivity separated by single nights of activity between Feb 16 and Apr 12 2015. When the bat was active between December 2014 and March 2015, it was generally active for $<10 \%$ of each night (Table 1). During the period from Feb 03 to Apr 12 2015 the bat began flight activity an average of 53 minutes (range: 37-77 minutes) after sunset and was active for an average of 54 minutes (range: $30-80$ minutes) (Fig. 4).

By comparing tag temperatures to ambient temperatures at weather stations in the region (Figs S1 and 2) we inferred that the yellow-tagged bat likely overwintered in the vicinity of where we captured it. Excluding two arousals that were not associated with flight, mean temperature of the tag during the 40 -day inactive period that included January was $10.1^{\circ} \mathrm{C}$ (range $=1-23$ ). On average, the tag was $0.9^{\circ} \mathrm{C}$ (range $=-7.0-9.0$ ) warmer than air temperatures at KFOT station $(25 \mathrm{~km}$ NNW of capture area) and there was strong temporal correlation between the two temperatures $(r=0.88$, Fig. 2$)$ indicating that the bat was in torpor during this time. Similarly the bat remained in torpor during an 18-day period in mid-March despite the mean temperature of the tag reaching $14.3^{\circ} \mathrm{C}$ (range $=8-27$ ). We recorded 20 arousals from torpor by the bat between Nov 022014 and Apr 122015 (Fig. 4), 4 of which were not associated with flight. Arousals were more frequent and generally longer in duration during November and December than during January-April when they occurred, on average, 12 days apart. The mean duration of arousals over the entire winter was 199 (range 55-385) minutes. 


\section{Discussion}

We used two new types of technology to assess the ecology and behavior of hoary bats during migration and over-wintering. GPS tags allowed us to determine that some individuals make long distance, multi-directional movements during autumn while data loggers allowed us to demonstrate that hoary bats can engage in winter-long hibernation.

The three male hoary bats we followed exhibited a variety of movement behaviors during autumn. For one bat we had no evidence that it vacated the general vicinity of where it was captured, whereas another bat flew at least $68 \mathrm{~km}$ straight line distance in single night and a third completed a $>1000-\mathrm{km}$ circumnavigation of northern California, Oregon, and Nevada over the course of a month. Hence our results demonstrate the possibility that some individuals may not engage in relatively simple, directional movements during autumn. The reason for long-distance, round trip travel exhibited by the male hoary bats in our study is enigmatic. It is possible that the long-distance movements we documented were associated with bats seeking favorable conditions of temperature and humidity for roosting and foraging ${ }^{39}$. Although this explanation may account for movements to and from areas dozens of $\mathrm{km}$ away, it does not seem sufficient, energetically, to explain movements of $>300 \mathrm{~km}$ from the study area. Another hypothesis, based on synchrony between autumn migration and mating readiness in hoary bats ${ }^{40}$, is that the male bats we tracked were trying to intercept and mate with females migrating to wintering grounds.

Hoary bats are inarguably a migratory species, yet we have shown with a single individual that they are capable of hibernating for a period of 6 months during winter. Although early laboratory research indicated that species of Lasiurus may be well-adapted for hibernation ${ }^{41}$, subsequent observations of free-ranging hoary bats using radio-telemetry had only documented multi-day bouts of torpor during summer ${ }^{42}$ and periods lasting less than one month during winter in eastern red bats (Lasiurus borealis) ${ }^{43,44}$. The number and length of torpor bouts and frequency of arousal we observed in a male hoary bat, particularly in late-winter, was generally similar to what has been observed for bats hibernating in caves and mines ${ }^{45-47}$. In fact, the bat we monitored remained in hibernation despite ambient temperatures at which it was active in the study area during autumn and which insect prey was likely available. Furthermore, the bat appeared to retain its circadian rhythm, because its arousals coincided with sunset (Fig. 4). Maintenance of a dusk-arousal circadian rhythm throughout winter has also been documented in cave-hibernating bats that live in regions with mild winters, whereas hibernating cave bats in regions with harsher winters tend to lose dusk-arousal rhythms during mid-winter ${ }^{45,48,49}$. Further, on 4 occasions the bat re-warmed without taking flight demonstrating that, as in other hibernating bats, arousals can be motivated by needs other than feeding ${ }^{49}$. These observations support the suggestion that hibernation is a conserved trait in temperate-zone bat species ${ }^{50}$. Knowledge that hoary bats can move long distances in non-linear ways and hibernate during winter may have practical impacts. For example, hoary bats frequently collide with wind turbines during autumn ${ }^{51}$ and are currently presumed to be safe from white-nose syndrome, an emerging disease that heretofore has only impacted cave-hibernating bats ${ }^{52}$. Continued use and enhancement of the tracking technologies we demonstrated on hoary bats could help advance understanding of bat biology, as well as some of the most important conservation issues currently involving bats.

\section{Methods}

Tag Attachment. We attached two types of tags to bats: programmable GPS tags with and without VHF transmitters (Pinpoint 8, Lotek Wireless, Newmarket, Ontario, Canada), and data logger tags (GDL3, Swiss Ornithological Institute, Sempach, Switzerland). The GPS-only tags weighed $1.1 \mathrm{~g}$ and had dimensions of $22.0 \mathrm{~mm} \times 11.0 \mathrm{~mm} \times 4.5 \mathrm{~mm}$ with a posterior-extending antenna $43 \mathrm{~mm}$ in length. The GPS tags were programmed to record location on 8 specified dates and times. Five GPS tags also included VHF transmitters (PicoPip AG317, Lotek Wireless, Newmarket, Ontario, Canada). Those tags weighed $1.4 \mathrm{~g}$, and had dimensions of $20.5 \mathrm{~mm} \times 15.0 \mathrm{~mm} \times 6.0 \mathrm{~mm}$ with an additional posterior-extending antenna $145 \mathrm{~mm}$ in length. VHF transmitters were intended to help establish which animals were still in the study area during the first month after attachment. Both types of GPS tags were re-chargeable and re-programmable without removing the tag from the bat. We programmed GPS tags to record nighttime locations approximately 1 hour after local sunset, and daytime locations at noon. Data from GPS tags consisted of date and time of position, an estimate of tag location in 3 dimensions, PDOP a measure of location accuracy, and the time required to acquire position information. We estimated GPS location precision as approximately $\pm 200 \mathrm{~m}$ based on tests conducted at ground level using tags that were both stationary and in motion.

We also attached $1.14 \mathrm{~g}$ data loggers with dimensions of $24.0 \mathrm{~mm} \times 10.0 \mathrm{~mm} \times 4.0 \mathrm{~mm}$ to hoary bats. The tags included a $5 \mathrm{~mm}$ long light sensor that extended dorso-caudally. Data loggers recorded light-level and animal activity via accelerometer, every 5 minutes similar to those used by Liechti et al. ${ }^{11}$; both values are relative, dimensionless, values. Temperature $\left({ }^{\circ} \mathrm{C}\right)$ was measured at the dorsal surface of the tag every 30 minutes and was a mixture of ambient temperature and bat body temperature. Although temperature readings did not allow us to precisely determine bat body temperature, we were able to determine when hoary bats were euthermic either by comparison of tag temperature data to patterns in ambient temperature measured by weather stations (Fig. 2, Supplementary Information) and/or corresponding patterns in tag activity data indicating bat movement (Fig. 3). Tag temperature approximated ambient temperature when a bat was inactive and thermoconforming and increased above ambient when the bat was inactive but euthermic (Fig. S3) and when the tag was in direct sunlight.

We attached both types of tags to bats from Sep 22-27 2014. We captured hoary bats in mist nets along the channel of Bull Creek in Humboldt Redwoods State Park, California (latitude: 40.35, longitude: -124.01). Bats were captured in standard 2.6-m high mist nets and in a triple-high configuration with three standard mist nets stacked on top of one another. We attached tags to adult male hoary bats, which comprise $>95 \%$ of captures at this site, selecting individuals with the highest mass captured on a given night. We attached tags to the dorsum, 
caudal to the scapulae and cranial to the pelvis using sutures following the methods of Castle et al. ${ }^{53}$. Bats were released at the capture site after allowing them 20 minutes to recover from anesthesia. Bats to which tags were attached did not exhibit unusual levels of mass loss, skin irritation, or mobility while entering roosts ${ }^{53}$.

We attempted to recapture tagged individuals using mist net surveys along the Bull Creek waterway on 19 nights between Sep 26 and Oct 19 2014, 13 nights between Oct 272014 and Apr 02 2015, and 22 nights between Apr 12 and 28 May 28 2015. When bats carrying GPS tags were recaptured during autumn 2014 we downloaded data and recharged and reprogrammed tags while they were attached to bats ${ }^{53}$. In contrast, recovery of data from data loggers required removal of the tag.

Bat capture and handling were carried out in accordance with guidelines of American Society of Mammalogists ${ }^{54}$ under permit with the California Department of Fish and Wildlife (\#SC-002911). Our experimental methods were approved by the Institutional Animal Care and Use Committee of the U.S. Geological Survey Fort Collins Science Center (FORT IACUC 2014-08).

Data Analysis. For data analysis we considered bats to be active when 5-min activity values exceeded a relative activity level of 6 (on a scale of 0-74), based on a comparison with activity levels logged during daylight hours when the bats were roosting. We considered the nighttime period to be the 5 -minute observations between sunset and sunrise in our study area, although this will be inaccurate if bats moved $>100 \mathrm{~km}$ from our study area. We considered the bat to be torpid when it was inactive and within $4^{\circ} \mathrm{C}$ of the temperature at a nearby weather station (Figs $\mathrm{S} 1$ and 2). We defined an arousal as a total increase of $\geq 3^{\circ} \mathrm{C}$ in tag temperature that occurred at night in the absence of similar increase in ambient temperatures at nearby weather stations.

\section{References}

1. Fleming, T. H. \& Eby, P. In Bat Ecology (eds Kunz, T. H. \& Fenton, M. B.) 156-208 (The University of Chicago Press, 2003).

2. Baker, R. R. The evolutionary ecology of animal migration (Holmes \& Meier Publishers, 1978).

3. Lanzone, M. J. et al. Flight responses by a migratory soaring raptor to changing meteorological conditions. Biology Letters $\mathbf{2 0 1 2 , 5}$ (2012).

4. Sullivan, B. L. et al. The eBird enterprise: an integrated approach to development and application of citizen science. Biological Conservation 169, 31-40 (2014).

5. Hobson, K. A. \& Wassenaar, L. I. Tracking animal migration with stable isotopes (Elsevier, 2008).

6. Hallworth, M. T. \& Marra, P. P. Miniaturized GPS tags identify non-breeding territories of a small breeding migratory songbird. Scientific Reports 5, 11069 (2015).

7. Stutchbury, B. J. et al. Tracking long-distance songbird migration using geolocators. Science 323, 896 (2009).

8. Liechti, F. et al. Timing of migration and residence areas during the non-breeding period of barn swallows Hirundo rustica in relation to sex and population. Journal of Avian Biology 46, 254-265 (2014)

9. Wolfe, J. D. \& Johnson, E. I. Geolocator reveals migratory and winter movements of a Prothonotary Warbler. Journal of Field Ornithology 86, 238-243 (2015).

10. Kays, R., Crofoot, M. C., Jetz, W. \& Wikelski, M. Terrestrial animal tracking as an eye on life and planet. Science 348, aaa2478, doi: 10.1126/science.aaa2478 (2015)

11. Liechti, F., Witvliet, W., Weber, R. \& Bächler, E. First evidence of a 200-day non-stop flight in a bird. Nature Communications 4, 2554 (2013).

12. Wilson, A. D. M., Wikelski, M., Wilson, R. P. \& Cooke, S. J. Utility of biological sensor tags in animal conservation. Conservation Biology 29, 1065-1075 (2014).

13. Faaborg, J. et al. Recent advances in understanding migration systems of New World land birds. Ecological Monographs 80, 3-48 (2010).

14. Weller, T. J., Cryan, P. M. \& O'Shea, T. J. Broadening the focus of bat conservation and research in the USA for the 21 st century. Endangered Species Research 8, 129-145 (2009).

15. Eisentraut, M. Ergebnisse der Fledermausberingung nach dreijähriger Versuchzeit. Z. Morphol. Okeol. Tiere 31, 1-26 (1936).

16. Griffin, D. R. Migrations of New England bats. Bulletin of the Museum of Comparative Zoology 86, 217-246 (1940).

17. Ellison, L. E. Summary and analysis of the U.S. government Bat Banding Program. U.S. Geological Survey Open-File Report 2008-1363, 1-117 (2008).

18. Hutterer, R., Ivanova, T., Meyer-Cords, C. \& Rodrigues, L. Bat migrations in Europe: a review of banding data and literature (German Agency for Nature Conservation, 2005).

19. Steffens, R., Zöphel, U. \& Brockmann, D. 40th anniversary Bat Marking Centre Dresden - evaluation of methods and overview of results (Saxon State Office for Environment and Geology, 2007).

20. Ahlén, I., Baagøe, H. J. \& Bach, L. Behavior of Scandinavian bats during migration and foraging at sea. Journal of Mammalogy 90 , 1318-1323 (2009).

21. Petersons, G. Seasonal migrations of north-eastern populations of Nathusius' bat Pipistrellus nathusii (Chiroptera). Myotis 41-42, 29-56 (2003)

22. Cryan, P. M. Seasonal distribution of migratory tree bats (Lasiurus and Lasionycteris) in North America. Journal of Mammalogy 84, 579-593 (2003).

23. Findley, J. S. \& Jones, C. Seasonal distribution of the hoary bat. Journal of Mammalogy 45, 461-470 (1964).

24. Petit, E. \& Mayer, F. A population genetic analysis of migration: the case of the noctule bat (Nyctalus noctula). Molecular Ecology 9 , 683-690 (2000)

25. Russell, A. L., Medellin, R. A. \& McCracken, G. F. Genetic variation and migration in the Mexican free-tailed bat (Tadarida brasiliensis mexicana). Molecular Ecology 14, 2207-2222 (2005).

26. Dechmann, D. K. N. et al. Tracking post-hibernation behavior and early migration does not reveal the expected sex-differences in a "female-migrating" bat. PLoS ONE 9, e114810 (2014).

27. McGuire, L. P., Guglielmo, C. G., Mackenzie, S. A. \& Taylor, P. D. Migratory bat stopover in the long-distance migrant silver-haired bat, Lasionycteris noctivagans. Journal of Animal Ecology 81, 377-385 (2011).

28. Baerwald, E. F., Patterson, W. P. \& Barclay, R. M. R. Origins of migratory patterns of bats killed by wind turbines in southern Alberta: evidence from stable isotopes. Ecosphere 5, 1-17 (2014).

29. Cryan, P. M., Stricker, C. A. \& Wunder, M. B. Continental-scale, seasonal movements of a heterothermic migratory tree bat. Ecological Applications 24, 602-616 (2014)

30. Fleming, T. H., Nunez, R. A. \& Sternberg, L. S. L. Seasonal changes in diets of migrant and non-migrant nectarivorous bats as revealed by carbon stable isotope analysis. Oecologia 94, 72-75 (1993). 
31. Fraser, E. E., McGuire, L. P., Eger, J. L., Longstaffe, F. J. \& Fenton, M. B. Evidence of latitudinal migration in tri-colored bats, Perimyotis subflavus. PLoS ONE 7, e31419 (2012).

32. Voigt, C. C., Popa-Lisseanu, A. G., Niermann, I. \& Kramer-Schadt, S. The catchment area of wind farms for European bats: a plea for international regulations. Biological Conservation 153, 80-86 (2012).

33. Richter, H. V. \& Cumming, G. S. First application of satellite telemetry to track African straw-coloured fruit bat migration. Journal of Zoology 275, 172-176 (2008).

34. Smith, C. S. et al. Satellite telemetry and long-range bat movements. PLoS ONE 6, e14696 (2011).

35. Griffin, D. R. In Biology of bats Vol. 1 (ed Wimsatt, W. A.) 233-264 (Academic Press, 1970).

36. Shump, K. A. Jr. \& Shump, A. U. Lasiurus cinereus. Mammalian Species 185, 1-5 (1982).

37. Dalquest, W. W. Seasonal distribution of the hoary bat along the Pacific Coast. Murrelet 24, 21-24 (1943).

38. Cryan, P. M. \& Veilleux, J. P. In Bats in forests: conservation and management (eds Lacki, M. J., Hayes, J. P. \& Kurta, A.) 153-175 (The Johns Hopkins University Press, 2007).

39. Cryan, P. M. \& Wolf, B. O. Sex differences in the thermoregulation and evaporative water loss of a heterothermic bat, Lasiurus cinereus, during its spring migration. Journal of Experimental Biology 206, 3381-3390 (2003).

40. Cryan, P. M. et al. Evidence of late-summer mating readiness and early sexual maturation in migratory tree-roosting bats found dead at wind turbines. PLOS ONE 7, e47586 (2012).

41. Davis, W. H. \& Reite, O. B. Responses of bats from temperate regions to changes in ambient temperature. Biological Bulletin 132, 320-328 (1967).

42. Willis, C. K. R., Brigham, R. M. \& Geiser, F. Deep, prolonged torpor by pregnant, free-ranging bats. Naturwissenschaften 93 , 80-83 (2006).

43. Mormann, B. M. \& Robbins, L. W. Winter roosting ecology of eastern red bats in southwest Missouri. Journal of Wildlife Management 71,213-217 (2007).

44. Saugey, D. A., Vaughn, R. L., Crump, B. G. \& Heidt, G. A. Notes on the natural history of Lasiurus borealis in Arkansas. Journal of the Arkansas Academy of Science 52, 92-98 (1998).

45. Czenze, Z., Park, A. \& Willis, C. K. R. Staying cold through dinner: Cold-climate bats rewarm with conspecifics but not sunset during hibernation. Journal of Comparative Physiology B 183, 859-866 (2013).

46. Jonasson, K. A. \& Willis, C. K. R. Hibernation energetics of free-ranging little brown bats. Journal of Experimental Biology 215, 2141-2149 (2012).

47. Reeder, D. M. et al. Frequent arousal from hibernation linked to severity of infection and mortality in bats with white-nose syndrome. PLoS ONE 7, e38920 (2012).

48. Hope, P. R. \& Jones, G. Warming up for dinner: torpor and arousal in hibernating Natterer's bats (Myotis nattereri) studied by radiotelemetry. Journal of Comparative Physiology B 182, 569-578 (2012).

49. Speakman, J. R. \& Thomas, D. W. In Bat ecology (eds Kunz, T. H. \& Fenton, M. B.) 430-490 (University of Chicago Press, 2003).

50. Geiser, F. \& Stawski, C. Hibernation and torpor in tropical and subtropical bats in relation to energetics, extinctions, and the evolution of endothermy. Integrative and Comparative Biology 51, 337-348 (2011).

51. Arnett, E. B. \& Baerwald, E. F. In Bat Evolution, Ecology, and Conservation (eds Adams, R. A. \& Pederson, S. C.) 435-456 (Springer, 2013).

52. Frick, W. F. et al. An emerging disease causes regional population collapse of a common North American bat species. Science 329, 679-682, doi: 10.1126/science.1188594 (2010).

53. Castle, K. T., Weller, T. J., Cryan, P. M., Hein, C. D. \& Schirmacher, M. D. Using sutures to attach miniature tracking tags to small bats for multimonth movement and behavioral studies. Ecology and Evolution 5, 2980-2989 (2015).

54. Sikes, R. S., Gannon, W. L. \& Mammalogists, A. C. a. U. C. o. t. A. S. o. Guidelines of the American Society of Mammalogists for the use of wild mammals in research. Journal of Mammalogy 92, 235-253 (2011).

\section{Acknowledgements}

Funding for this project was provided by the USDA Forest Service Pacific Southwest Research Station and U.S. Geological Survey, Fort Collins Science Center. We are grateful to the California State Parks, North Coast Redwood District for granting us access and permission to conduct this study. We thank A. Brokaw, J. Clerc, T. Dewey, B. Fahey, M. Lau, C. Long, M. McKenzie, S. Mendia, M. Parker, K. Southall, V. Stover, J. Szewczak, and C. Zurek for invaluable assistance in the field. J. Baldwin prepared the figure on arousal times. Special thanks to R. Diehl for sacrificing his chance to deploy experimental data loggers on birds and instead contributing them to advancement of knowledge regarding the other class of extant flying vertebrates. Comments from B. Zielinski and J. Wolfe improved the manuscript. Any use of trade, firm, or product names is for descriptive purposes only and does not imply endorsement by the U.S. Government.

\section{Author Contributions}

T.J.W., P.M.C., K.T.C., M.R.S. and C.D.H. conceived the study. T.J.W., K.T.C. and C.D.H. participated in field work. F.L. provided data loggers and helped interpret the data. T.J.W. analyzed the data. T.J.W. and P.M.C. wrote the manuscript with the participation of all authors. All authors were involved in the discussion and manuscript revision.

\section{Additional Information}

Supplementary information accompanies this paper at http://www.nature.com/srep

Competing financial interests: The authors declare no competing financial interests.

How to cite this article: Weller, T. J. et al. First Direct Evidence of Long-distance Seasonal Movements and Hibernation in a Migratory Bat. Sci. Rep. 6, 34585; doi: 10.1038/srep34585 (2016).

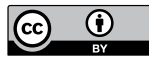

This work is licensed under a Creative Commons Attribution 4.0 International License. The images or other third party material in this article are included in the article's Creative Commons license, unless indicated otherwise in the credit line; if the material is not included under the Creative Commons license, users will need to obtain permission from the license holder to reproduce the material. To view a copy of this license, visit http://creativecommons.org/licenses/by/4.0/

(c) The Author(s) 2016 